\title{
Puesta en escena y arte: Lock-Out de César Vallejo
}

\author{
Martha Barriga Tello \\ Departamento Académico de Arte
}

Escrita en 1930, en francés, y prolijamente corregida, Lock-Out constituye un interesante ejemplo de las propuestas estéticas de César Vallejo expresadas hasta 1930, al punto de estimarla como un manifiesto de sus postulados teóricos sobre el arte teatral. La obra nunca se escenificó a pesar del empeño de su autor. El montaje virtual que proponemos se basa en las acotaciones directas e indirectas que aparecen en el texto,en las que César Vallejo puso especial cuidado, en el desarrollo del texto dialógico y en el estudio de sus escritos te6ricos sobre los mismos aspectos que trataremos aquí: las artes plásticas, la arquitectura y la música. A partir de la definición y presupuestos teóricos de $\mathrm{Va}$ llejo para la puesta en escena, encontramos una marcada preocupación por incorporar técnicas de otras artes diferentes al teatro, en la búsqueda de la obra de arte «integral» que estimulaballacicreación a principios del siglo $\mathrm{XX}$ en Europa.Para efectos del análisis hemos considerado como Actos los que César Vallejo señala como Escenas por no corresponder exactamente éstas a las escenas propiamente dichas, sino a los actos, al interior de los cuales se identifican las diferentes escenas.

La teoría del análisis teatral concuerda en que «el teatro es accion» (Romera, 116), que «es el dominio de la acción sobre el relato» (Helbo, 77). La acción en el teatro se traduce en la puesta en escena, la «expresión visual» del texto dramático (Loc. cit.). El texto es utilizado como «un esquema proyectual y la puesta en escena como un proceso de decodificación y reescritura» (Romera, 176). La importancia de la puesta en escena, de la representación, radica en su posibilidad de operar el montaje expresado en el texto a través de elementos que adquieren carácter significativo. Aunque es responsabilidad del director y

Letras (Lima), 95-96: 9-31, 1998. 
los actores,el dramaturgo puede imponer ciertos criterios por medio de las acotaciones, especificando características de los personajes, del escenario, el decorado, la música, el sonido, la luz, el color y otros aspectos con los que buscará orientar la representación, preservar el sentido de su texto y clarificar su comprensión. Cualquier modificación sustancial que el director o los actuantes realicen en estos aspectos puede derivar en la desvirtuación del mensaje contenido en el texto y, eventualmente, presentar una tesis radicalmente opuesta. César Vallejo fue consciente de la importancia de estas guías en la representación teatral y pretendió, con minuciosidad y detalladas especificaciones, que «la trascendencia y efecto artístico» (Vallejo, 1987: 359) de su obra fuera sometida a un mínimo de variación, ya que conocía que podría sufrir importantes transformaciones según se manejaran los elementos escénicos. El simple decorado no colmaba sus espectativas. Debía cumplir exigencias de «fuerza... originalidad... auténtica realidad» (Ibid., 431).

Lock-Out está planteada como obra contemporánea realista. Expone y desarrolla una tesis que afirma en toda su extension. Es una obra cerrada en la que la anécdota se inicia y se resuelve en escena. La estructura compleja de la obra combina con la propuesta de espacios simultáneos en los que se desarrollan las escenas. Se recurre en ocasiones a la luz para remarcar la correspondencia entre escenas que se refuerzan en su sentido. Los movimientos son recios y dinámicos en las escenas climáticas, o intensamente emotivas en las complementarias acompañadas de muchả actiontextema,fisica,atiravés de gestos actitudes y modulaciones de la vQz. De iggal celieved lésla acciós interna, invisible, producida en el cambio, transformación y desenvolvimiento íntimo de los personajes. La obra supone un espacio escénico funcional y realista orientado a quebrar la distancia entre la realidad objetiva conocida por el espectador, y aquella ficcionalizada en escena y, por lo tanto, distanciada de su referente inmediato. Su finalidad está determinada en su eficacia como medio de propaganda tanto como incentivo para la toma de consciencia revolucionaria. La puesta en escena que César Vallejo propone busca reforzar el mensaje, por lo que decidió incorporar todos los medios de los que su experiencia disponía para lograr su objetivo. 
Uso de los medios de otras artes

Música

«Sincronizando especialmente con el ruido de los motores y con los ruidos del taller en general, Pas d'acier de Prokofiev. Todos los obreros se hallan vestidos de gris y negro. Relámpagos metálicos de color surcan los espacios en sombra. Todo se mueve según un movimiento natural de rítmica armonía.

Efecto general de ballet.Cesa Pas d'acier, subsistiendo los ruidos del taller y algunas voces dispersas e intermitentes $(L O, 33)$ ».

Esta acotación da inicio a Lock-Out. Junto con la entonación masiva de La Internacional por los obreros en trance de huelga, ninguna otra pieza musical se volverá a oír en la obra a instancias de su autor. El sonido de las máquinas y las voces en diálogos y arengas tomarán su lugar. La «música del trabajo» es equiparable para Vallejo a la mejor pieza musical El Pas d'acier habíalo utilizado Sergiev Diaghilev en un montaje realizado en París en 1929 (Blanchard, 118-121). Este ballet, inspirado en la vida soviética, representaba la vanguardia del arte ruso y Diaghilev logró imponerlo-ntonces. Era una obra adecuada para Lock-Out, de gran vitalidad, El carácter grandioso de esta pieza imprime al movimiento de los actores una carga de quietud e inocencia simbólicas representadas en el trabajo y" que presagía, por la misma orfentación musical, la violencia que se desencadenará posteriormente cuando esta rítimica armonía sea quebrada ante la inminencia de la pérdida del trabajo.

Aunque la aparición de la música es circunstancial observamos que cumple también la función de ambientar, dar ritmo al movimiento actoral y, en el caso de la pieza de Prokofiev, contemporánea a la obra, definirla en el tiempo. Igualmente incide en el sentido épico de Lock-Out el que los obreros entonen La Internacional hasta en dos oportunidades. Finalizando el tercer Acto «Todos al salir, entonan La Internacional, mientras se escucha el trotar de la caballería» (69). Y al final cuando «Los obreros entrando en la fábrica [...] cantan La Internacionals (91).

En las escenas del cabaret en el cuarto Acto se menciona la presencia del "Tango» (80). La orquesta prevista para esta escena, la segunda del cabaret, debe estar ejecutando, probablemente, un tango cuando se inicia, porque César 
Vallejo acota: «La orquesta deja de tocar» (81), para luego, avanzada la escena señalar: «La música se reinicia» (82). La función de la música es aquí ambiental, expresiva.

\section{Cine}

En el transcurso de Lock-Out destaca el empleo de técnicas que conforman lo que conocemos como el lenguaje cinematográfico. Entre otras experiencias en este sentido César Vallejo debió alcanzar a ver La huelga (Stacka, 1924), de Sergei Eisenstein que fue premiada en 1925 en la Exposición de Artes Decorativas de París (Gubern, 221). La película aborda el proceso de una huelga de obreros en una fábrica metalúrgica, que termina con una matanza en manos de los soldados zaristas. Eisenstein admitió que en ella pudo practicar las propuestas innovadoras que había intentado, sin éxito, en la obra teatral Máscara de gas. La acción colectiva de la masa configurada como héroe, opuesta diametralmente al individualismo de la burguesía, debía ser representada ampliamente y para elloel teatro no brindaba las facilidades técnicas necesarias. En esta línea había avanzado el teatro ruso, con su búsqueda del realismo extremo y aquella por laque intentaba expresarse César Vallejo. Su preocupación por la solidaridad de la masa obrera es la fuerza orientadora de Lock-Out. Logró combinar en ella la actividad colectiva con los problemas humanos individuales quel debỉaafrontar el obre@tLas coincidencias en la búsqueda de soluciones pararesolvec pioblemas formales , lo acercan a los realizadores rusos, tanto del teatro como del cine.

El empleo de la masa como personaje en Lock-Out, con carácter colectivo en acción colectiva, impulsada por un ideal que le da coherencia y límites precisos, lleva la obra a la técnica cinematográfica. Fue el cine el que incursionó en los grandes planos que hacían participar a grupos numerosos, constituidos coherentemente, con una intencionalidad definida. La dificultad de conseguir similares resultados en escena hizo a Vallejo suplir la limitación recurriendo, en determinadas secuencias, a acciones tras bambalinas, en concordancia con los usos del teatro tradicional. Igualmente recurre a la alternancia de escenas en una secuencia, con la finalidad de reforzar los contenidos o contrastarlos. Los rápidos cambios de acción y la fugacidad de las escenas intercaladas, nos remiten a una técnica más cercana al cine que al teatro. Cinematográficamente, a través del montaje, este tipo de escenas referenciales son frecuentes. En LockOut César Vallejo intenta el mismo efecto por medio de la luz, iluminando o 
apagando determinado sector del escenario en el que la acción se produce. Este procedimiento era frecuente en la estética de puesta en escena expresionista, la que lo tomó a su vez del cine. En Lock-Out es un medio para remarcar significados, antes que una opción estética. Es en el cuarto acto donde más se utiliza este recurso. En él los sucesos ocurren en el lapso de un mes, por lo que debemos atribuirlo, además, a una manera de señalar el transcurso del tiempo dramático.

El decorado teatral propuesto en Lock-Out deriva de doble influencia. Había señalado Vallejo los intentos de algunos grupos teatrales de vanguardia en París y otras ciudades europeas por modernizar la escena. Anhelaban un cambio y se esforzaban en ello lo suficiente como para orientar las tendencias y gustos del público. Para César Vallejo, fundamentalmente la inspiración provenía de «las directivas artísticas de Moscú, cuya grandeza teatral y posibilidades creatices inmediatas no tienen en estos momentos rivales en el mundo» (1987: 360). La vanguardia provenía de Moscú y Vallejo mismo fue un entusiasta en aplicar sus principios. Esta innovación, lejos de reducirse al teatro, incorporaba el lenguaje cinematográfico como opción. Defendía la independencia del cine y rechazaba la tendencia que consideraba perniciosa, de teatralizarlo, de apartarlo de lo que le era intrínseco como arte, «el silencio». Esta diferencia, para él sustantiva, entre un género y otro, debería preservarse. Aunque se opuso a la utilización propagandística del «teatro fascista y el cine

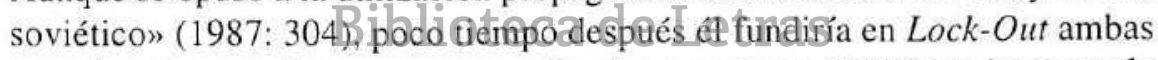
experiencias, precisamente para aplicarlåscoun tema dirigido a despertar la consciencia política del espectador, en beneficio de una propuesta ideológica definida. Esto le permitió logros semánticos que difícilmente hubiesen sido posibles por la manera tradicional. «Formas esencialmente colectivizantes de espectáculos, como el teatro de masas o los coros hablados» (Blanchard, 125) que estaban en la preocupación de los creadores contemporáneos a Vallejo.

Algunos detalles técnicos transmitidos en las acotaciones nos remiten también al lenguaje cinematográfico. Expresiones como

«(El ministro le fija una mirada despavorida)» $(L O, 49)$

«(Pese a que trata de evitarlo, estalla en sollozos)» (69)

«masca algunas migas que ha encontrado en un cajón:» (77)

«(El niño, que ha encontrado tres o cuatro habichuelas secas, las casca ruidosamente...)» (Loc. cit.).

«(Eleva en alto el billete de mil francos)» (81) 
"(...Brunot evoluciona en medio de los bailarines, deslizando billetes de mil francos en las blusas de las mujeres)» (82)

«bajo, con los ojos extrañamente brillantes:» (84)

«(con las cejas fruncidas)» (91)

están pensadas en términos cinematográficos de un primer plano, ya que son imperceptibles desde un escenario de las características que el autor propone. Otro elemento en este sentido lo constituye la calle en el Acto cuarto. Está propuesta para aparecer convencionalmente en el primer piso, encima de la planta baja, en la división central. Su posición, alejada del suelo, destaca nítidamente aquello que suceda en este espacio elevado y central. Equivale, salvando las distancias del medio, a lo que en cine es un «acercamiento», o gran plano. Aquí se destaca una escena, o un aspecto de la escena, que en realidad debía suceder a nivel del piso del escenario. Por otra parte su función es la de servir de nexo entre las habitaciones de los obreros, la calle y los acontecimientos que suceden allí y que, a nivel masivo, se dan en el piso inferior del escenario.

Ballet

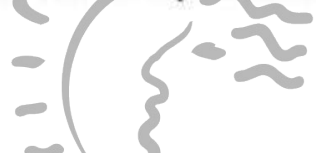

"Todo se mueve según un movimiento natural de rítmica armonía. Efecto general de ballet» $(L O, 33)$.

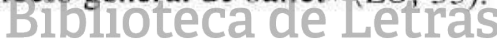

Al uso de la múşicagde balletidel Pas diacien acompaña el movimiento correspondiente, cadencioso, sencillo y sobrio que suscita esta pieza. La «rítmica armonía» caracteriza los movimientos iniciales. Posteriormente el movimiento de actores, con llegar a ser violento y dramático, deberá bastarse a sí mismo, sin ningún sonido referencial: «la danza que dance la danza» (Vallejo, 1987: 53), su independencia de la música. Encontramos también que en los "Relámpagos metálicos de color surcan los espacios en sombra» $(L O, 33)$ hay un estrecha relación entre color y música, lo que constituía credo estético en la época. En Lock-Out brinda a la escena un carácter plástico vinculado al objeto «máquina», en tanto su calidad de «metálico», y a la energía que acompaña al trabajo. La combinación de luces y sombras añade un elemento que va creando un espacio que expresa el movimiento dinámico en la solución futurista, con el dramatismo expresionista, sin que ello signifique una opción estética para la pieza en su conjunto. 
La luz, como elemento escénico, adquirió gran importancia durante la primera parte del siglo XX, por su novedad y lo desconocido de sus futuras posibilidades. Llegaron a plantearse innovaciones audaces a partir del juego de luces y su producción escénica. Se fue advirtiendo que los reflectores, organizadamente dirigidos, podían crear espacios y delimitar zonas con una facilidad e inmediatez no factible con otros recursos escenográficos. La luz creaba atmósfera. Confería dinamismo así como amplias posibilidades cromáticas y estilísticas a las escenas, reforzando la capacidad actoral de transmitir el efecto dramático de la obra. La inquietud de los directores de escena, de reflejar el mundo cambiante y tecnológico que los rodeaba, encontró en la luz un medio apropiado. Los haces luminosos de colores interseccionados en múltiples combinaciones, interpretaban adecuadamente el signo del mundo moderno. Los experimentos en este sentido fueron paralelos a los realizados con otros elementos escénicos. La creatividad de los artistas los llevó a romper esquemas y a intentar, con luz y cuerpos volunninosos abstractizados, la ambientación necesaria a cualquier puesta en escena.

Más comúnmente las tentativas se orientaban a reforzar el carácter autónomo de los medios escenográficos y de la puesta en escena en general, sobre todo en la creación de nuevos tiempos y espacios, lejos de la imitación servilmente realista. HĐỷ sabomes que la posibilidad plástica de la luz es amplia, por sí misma, o en combinación con el color. No ocupa espacio pero los crea a libertad. Encubre, disfraza o transforma los elementos escenográfícos ilimitadamente. Afecta al mobiliario, la utilería, el vestuario, el maquillaje. Forma o deforma, evidencia o esconde, resalta o minimiza. Plana, ejerce sobre la escenificación un efecto de crudo y descarnado que influye directamente en las expectativas del público. En matices de intensidad crea diferentes atmósferas, según incida en uno u otro aspecto del montaje. La luz debe, en consecuencia, manejarse en concordancia con el sentido ideológico de la obra, no debe desvirtuarlo o serle indiferente. En 1930 las posibilidades de la luz estaban descubriéndose. Permitía destacar momentos climáticos, tal como la incipiente técnica cinematográfica estaba logrando. Por el juego de luces propuesto en las acotaciones, Lock-Out está organizada temporalmente de acuerdo al uso que se le da a la luz, en cada uno de sus actos:

ACTO $\mathrm{N}^{\circ}$ 1: Transcurre en horas de la mañana, hasta el mediodía.

«No se puede ir al sindicato ahora, sino esta tarde [...]. Fijemos la reunión a las tres, por ejemplo,» $(L O, 37)$. 
Ligeras variaciones luminosas señalarán el paso del tiempo hacia el mediodía, pues los Obreros parece que se retiraron antes de las tres de la tarde propuesto

\section{MAN̄ANA ---TARDE HACIA EL MEDIODÍA}

(8 horas)

ACTO $N^{\circ}$ 2: Sucede antes del mediodía, con la entrevista entre el Ministro y los Industriales.Cuando se reunen los Delegados y Lebranc, será mediodía y las primeras horas de la tarde, lo que debe recrear la escena de los Obreros esperando agrupados delante del edificio

«Efectivamente, es mediodía... A la hora en punto...» $(L O, 52)$

ANTES DEL MEDIODÍA-MEDIODÍA-HORAS PRIMERAS DE LA TARDE

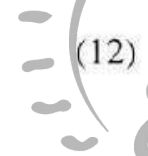

a

(13 a 15$)$

ACTO $N^{\circ}$ 3: Ocurre después de las primeras horas de la tarde, porque Biblioteca de Letras

«Se va, a daf euentadel cesultadadeda entrevista de los delegados obreros con los patrones y el Ministro de Trabajo» (55) y « iSon las cinco...» $(L O, 56)$.

La acción se inicia poco antes de esta hora ya que «nuestra entrevista con el Ministro ha sido muy breve» (57). El desarrollo de la pieza avanza hacia el anochecer, lo que podrá percibirse por el cambio de luz, la misma que, además, deberá remarcar la intensidad y violencia de las intervenciones que caldean los ánimos hacia el máximo al final del acto

\section{TARDE---------ANOCHECER}

ACTO N ${ }^{\circ} 4$ : César Vallejo señala «la calle se ilumina « $(L O, 71)$ sin especificar la hora. Queda a criterio del director el nivel de luminosidad que podrá usarse. 
Sin embargo es posible deducir que se trata de horas de la tarde por la frase

«... Por qué no me lo dijiste esta mañana...» y la acotación «La noche cae» $(L O, 76)$.

Para la escena del cabaret suponemos noche plena. En el local abandonado de la fábrica "Es ya de noche» y el Guardián se encuentra «dormido en un rincón» $(L O, 82)$ Se refuerza esta impresión porque la iluminación se reduce a las linternas que portan el Vigilante y la Policía

\section{ANOCHECER-..--.--NOCHE}

(24 horas)

ACTO N 5 :

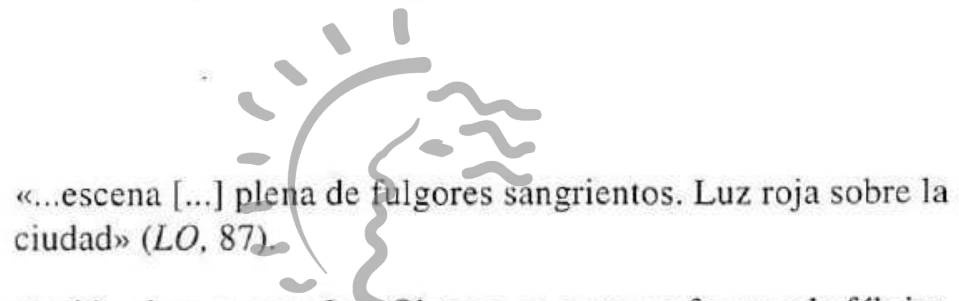

Señala esta acotación el amanecer. Los Obreros se agrupan frente a la fábrica antes de ingresar a trabạjår. Lâ luz tiene hōnda significación aquí, siendo definida la especificación de los colores cálidos Deberá aclarar progresivamente hasta su plenitud

\section{AMANECER------MAÑANA}

El ciclo temporal de la obra, que marcará la luz, corresponderá a los efectos secuenciales de un día común, independiente del tiempo escénico y el tiempo cronológico que la pieza propone en cada acto. Vallejo la inicia con efectos luminosos diurnos, avanzando hacia la luz total del mediodía y culmina con la oscuridad en el cuarto acto. El último acto «amanece» en escena, rememorando por medio de la luz el drama interior y adelantando con la luminosidad total de «...el sol aparece y es pleno día» $(L O, 87)$ el triunfo de los Obreros. 
Encontramos en la obra que el tiempo escénico comprende un ciclo luminoso correspondiente al movimiento de rotación terrestre, de amanecer a amanecer, independiente del tiempo dramático que transcurre en seis semanas repartidas en los cinco actos. Este efecto cíclico da coherencia y plasticidad al montaje a partir de los efectos de la luz, enmarcando la acción entre dos amaneceres. Una mañana tranquila es alterada por el anuncio del cierre de la fábrica y la reducción de los salarios. Las negociaciones se producen hacia el mediodía y primeras horas de la tarde. En horas avanzadas de la misma y hacia el anochecer, se toma la decisión del enfrentamiento sindical. La represión y la lucha se dan al anochecer y en la noche, con escenas de desesperación y muerte. La solución del conflicto sucede en la madrugada y, nuevamente, el amanecer y la mañana anuncian el triunfo de las acciones consecuencia de la huelga.

Según explicamos al inicio de esta sección, la luz cumple funciones varias en el montaje. Lock-Out las contempla en cada caso. Respecto a la capacidad de delimitar el lugar teatral y de crear atmósfera, encontramos

ACTO $N^{\circ}$ 1: «Relámpagos metáliéos de color surcan los espacios en sombra" ( $L O, 33)$. Por esta acotación suponemos un ambiente de trabajo no plenamente iluminado inicialmente, ya que hay espacios en penumbra sobre los que destacarán los rayos de luz metálica coloreada. Estos rayos surcarán el espacio entre los personajes. Comenzada la

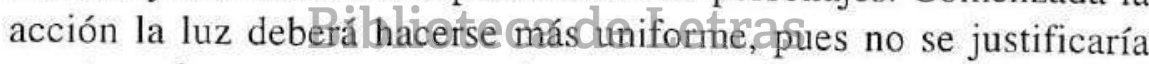
mantener los conträstes marcados birnuy definidos. Los «relámpagos metálicos de color» entendemos que se orientan a subrayar el tiempo moderno, tecnológico, en el que transcurre la obra. Puede igualmente demostrar la prosperidad de la fábrica ,haciendo más dramático el tema central de la pieza y orientando la opinión del público. Estos colores podrían escogerse entre los tonos azules, verdes y amarillos para señalar lo «metálico» y, adicionalmente, lo frío e inhumano del lugar.

ACTO No 2: La oficina del Ministro de Trabajo «se ilumina», sin mayores detalles. Debemos suponer que es una luz de mediana intensidad, neutra. Esta misma se empleará para las habitaciones secundarias, en las que se desarrollan las escenas entre los Industriales y los Delegados obreros, pues no sería apropiado utilizar luces secundarias como lámparas bajas u otras, ya que configurarían un ambiente de intimidad opuesto al de la obra en este Acto. En la planta baja los Obreros esperarán frente a la puerta del edificio. La hora es la del mediodía.La luz será vertical y cruda, salvo que se opte por los efectos dramá- 
ticos, que no nos parecen apropiados en este caso.

ACTO $N^{\circ} 3$ : La escena en el sindicato necesita luz igualmente uniforme pero con ciertos matices, a propósito de dos aspectos. En primer lugar que se trata de horas de la tarde y que irá oscureciendo. En segundo lugar que la atmósfera es «pesante» $(L O, 55)$, lo que supone enrarecer el ambiente. Paralelo a ello, la luz deberá remarcar los cambios y alteraciones de ánimo de los Obreros. Aquí sí es posible el uso dramático de la luz. Este Acto expone la tesis de su autor y todo recurso para propiciar su correcta percepción no debe desaprovecharse. Los colores preferibles pueden variar entre el amarillo (inocencia), gris (pureza, tristeza), blanco (pureza, transparencia) y rojo (decisión, coraje, fuerza) de apariencia mate o terrosa, para acentuar la condición laboral miserable del Obrero y lo extremo de la situación. Al finalizar el Acto la salida de los Obreros y la entrada de la Policía requiere, al contrario, luz blanca cruda con destellos rojonaranja.

ACTO $N^{\circ}$ 4: Este es el Acto más rico respecto a la luz. Se inicia cuando la calle "se ilumina $[\ldots]$. Atmósfera de pánico y muerte» $(L O, 71)$. Es de día, pero la acotación del autor nos obliga a imaginar un espacio plagado de sombras amenazantes y colores dentro de la variedad de verdes, cuya frialdad transmitiría el miedo y la presunción de muerte. Un tono gris-verde conferiría la «atmósfera de pánico» que se busca.

Las habitaciones de Pos obrefos estaran iluminadas tan débilmente como

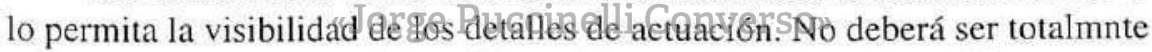
blanca porque desvirtuaría la ambientación y quebraría la voluntad de contraste con la escena del cabaret. La luz podrá matizarse en azules y amarillos, para acentuar la tristeza y la firme voluntad en grupos familiares de relación cálida y solidaria. El cabaret, sin embargo, se prestará a todos los extremos dramáti$\cos$ de la luz.La acotación «atmósfera típica» $(L O, 80)$ facilita el uso de colores cálidos (rojo, naranja, dorado, amarillo) y tonos estridentes de fuerza contrastante (verde, azul, negro). Estos remarcarán la superficialidad, frivolidad y lascivia del lugar. Los contrastes de luz y de color marcarán el desorden escénico, en el que zonas sombreadas o escasamente iluminadas, podrán acentuar su tenebrosidad. Esta libertad en el uso de la luz, deberá considerar detenidamente su efecto sobre los ya variados y contrastados colores del vestuario y del maquillaje de los actores.

Hacia el final del Acto la acción pasa al taller abandonado de la fábrica. La luz prácticamente está ausente, pues se recurre a linternas para iluminar la 
acción. Manteniendo la penumbra puede lograrse un fuerte efecto por la debilidad de la luz de la linterna -por lo menos mientras avanza el Vigilante hacia el Guardián y pueda acentuarse su presencia amenazante-e igualmente, cuando el Guardián cae muerto por intervención de la Policía. En el momento que el Vigilante deja en el piso la linterna que lleva, para defenderse, un reflector dirigido a destacar maniobras de lucha sería conveniente. Aunque César Vallejo parece haber imaginado la escena a oscuras cuando acota «Se escucha el forcejeo de la lucha» $(L O, 85)$. Esto sería innecesario en una escena iluminada. Si se acepta esta propuesta, entonces las linternas serán la única iluminación a que podrá recurrirse en esta secuencia, predominando el ambiente espectral. Vallejo gusta de las escenas totalmente a oscuras. El recurso lo propuso en Colacho Hermanos tiempo después, alternando la total oscuridad de una escena con otra inmediata en la que la luz de un fósforo, el destello de un cigarrillo o la débil iluminación de un lamparín eran la única fuente lumínica. Nuevamente en $\mathrm{La}$ piedra cansada la escena del asesinato se produce en la total oscuridad percibiéndose únicamente sonidos ahogados. La incompleta y promotora Mampar insinúa una escena similar en iguales condiciones. En Lock-Out no parece distinta la intención. En el momento final del cuarto Acto se iluminan todas las escenas juntas. Podrá emplearse la luz del farol que se menciona y que podrá prenderse desde las acotaciones «La noche cae. De rato en rato, pasa todavía alguno...» (76) y, posteriormente, «Un pelotón de guardias bajo la luz de un farol...» (Ibid. 8.1). A diferencia de la escena de la fábrica, en este caso no podrá emplearse exclusivamente fa luzdel farol. Esta deberá complementarse con la luz general.Jorge Puccinelli Converso »

ACTO $N^{\circ} 5$ : Este Acto propone efectos simbólicos de luz. La acotación «plena de fulgores sangrientos», nos remite tanto a la coloración cálida en rojos, naranjas y amarillos que deberá usarse, como, posiblemente, a un efecto luminoso complementado con aparición de nubes y el sol mismo. Nos inclinamos sin embargo a prescindir de este recurso por considerarlo incompatible con la estética del autor en esta obra. Sostenemos el sentido referencial de la acotación "Luego, lentamente, el sol aparece y es pleno día» $(L O, 87)$. En este momento se hará luz plena en el escenario acorde con la celebración y algarabía de los Obreros. Cuando se señala que después de algunos minutos «se oye el sonido de las máquinas», la luz puede repetir el efecto de colores metálicos del inicio del primer Acto. Esto conjugaría con el tiempo cíclico que mantiene la obra en su conjunto

«Al levantarse el telón, el taller de una fábrica metalúrgica en plena labor» (33: Acto $\mathrm{N}^{\circ} 1$ ) «[...]. Pasan algunos minutos y se 
oye el sonido de las máquinas puestas a funcionar» $(L O, 91$. Acto $\mathrm{N}^{\circ} 5$ ).

Artes plásticas: escultura: espacio escénico: luz

En cuanto a la delimitación del espacio escénico la luz en Lock-Out establece relaciones entre las escenas, las destaca o aísla, usándose inclusive para comparar ambientes y subrayar de este modo la propuesta del texto. Este recurso es usado en el segundo Acto y en el cuarto. En ellos se ilumina alternadamente los ambientes en los que se desarrollan las escenas, manteniendo en penumbra el resto del escenario. El juego con la luz nos remite a la técnica escultórica, destacando masas, volúmenes y espacios. La escultura formula su propuesta interactuando estos elementos y César Vallejo en sus acotaciones parece moldear las escenas igualmente

ACTO $N^{\circ}$ 2: En el edificio del Ministerio de Trabajo suceden varias escenas establecidas en base al sistema luminoso que hemos señalado

«Habiendo cerrado la puerta,da algunos pasos y se acomoda en su asiento. La luz de esta escena se apaga y se iluminan las tres salas del primer piso que-se comunican, así como también la fachada de laplantabaja del edificio ${ }_{f}[\ldots . .$. . Al momento en que se ilumina la sala de ta izquierda, Hegan... $\$(L O, 51)$

"Jorge Puccinelli Converso"

ACTO $N^{\circ}$ 4: En este Acto las combinaciones de luz suponen un rico entramado de escenas que se complementan, oponen o sirven de referencia para aquella que se está actuando

«Al levantarse el telón, la calle se ilumina (71).[...]. La multitud desaparece al surgir un grupo de guardias a caballo. Se oscurece la escena. Se ilumina la habitación de la izquierda.[...]. La escena de la calle se apaga.» $(L O, 73)$.

Mientras se desarrolla la escena en la habitación de la izquierda encontramos dos acotaciones que permiten,como referencia, remitirnos a escenas externas. Una es la mención, sin detalle de luz, que dice «La calle, en efecto, desierta» $(L O, 74)$. Llama la atención esta acotación toda vez que su autor nos ha dicho poco antes que la escena en la calle se apaga, con lo que desaparece de la acción dramática inmediata. Deberá tomarse en cuenta este aspecto. La segunda tiene carácter comparativo 
«Un huelguista abre el cuarto de la derecha que se ilumina inmediatamente. Está con su mujer y dos niños -de 4 y 6 años- que lloran. La madre ha corrido el cerrojo; el obrero pega la oreja a la puerta y escucha” (Loc. cit.).

La acción continúa en la habitación de la izquierda.S in embargo, deberá oscurecerse la de la derecha aunque no se acote al respecto, porque terminada la escena de la izquierda

«La obrera titubea un instante y luego, a su vez, se precipita afuera. Esta escena se oscurece. La pieza de la derecha se ilumina. Los niños lloran» $(L O, 76)$.

Durante la escena de la derecha «Un cojo atraviesa la calle huyendo...» (Loc. cit.) y se repite el caso anterior en la calle. Lo que se refrenda porque «De rato en rato, pasa todavía alguno, apurado y temeroson. Suponemos que esto facilitará la salida del padre de la habitación, pues más adelante (79) «En la calle pasan dos policías llevandose al Obrero 28», quien precisamente fue el que salió.

«Esta escena se apaga. El cabaret se ilumina (80) [...] El cabaret se apaga. De nuevo la calle obrera se ilumina. [...] La escena se oscurece. Se ilumina de nuevo el cabaret» (Ibid., 81).

La alternancia de la escena del cabaret con la de la calle obrera refuerzan entre sí el mensaje de la obra. Una sirve de comparación respecto a la otra. «...La escena se oscurece. Se ilumina la planta baja. Ahora se trata de una fábrica abandonada» (82). Finalmente el Acto culmina con una gran escena

«... El guardián cae abatido. La escena se apaga. Luego, se iluminan todas las escenas anteriores, simultáneamente: el cabaret, la pieza del obrero 28 , la calle popular donde yacen los cadáveres de la obrera 1 y de la madre 1 ; el cuarto donde al pie de la puerta solloza la madre, con el más pequeño de sus hijos dormido en los brazos y el mayor gimiendo en la cama; los talleres abandonados con el cadáver del guardián sobre el piso. El cabaret se halla paralizado: una lujuria repugnante y grotesca» (Ibid., $85)$.

El juego de luces que destaca determinadas escenas, sobre todo en el Acto cuarto, recuerda la técnica cinematográfica del acercamiento. Igualmente, 
tal como sucede en el cine, permite concentrar la atención en un aspecto del drama manteniendo en suspenso otros. Con la alternancia rápida y súbita de una escena muda al interior de la principal que lleva el diálogo, se acerca al montaje cinematográfico que permite seccionar escenas y turnarlas en una secuencia, cambiando el punto de vista, así como brindando información complementaria necesaria para la comprensión de la totalidad de la historia. Bien había señalado César Vallejo al referirse a la nueva técnica teatral que «El teatro de este modo funde en la escena los recursos elípticos del music-hall, del circo, de la danza y del cinema conjugados...» (1987: 304). Fundamentalmente en el cuarto Acto, en el que percibimos el dinamismo y la agitación del momento de la lucha sindical. La luz en Lock-Out tiene sentido dramático, en toda la obra. Remarca situaciones y define espacios, juega con los tiempos sin por ello perder verosimilitud. Crea atmósfera y orienta el ritmo de la pieza, la organiza y le da coherencia. Equilibra los espacios llenos y vacíos, destacando determinados elementos que buscando mantener la armonía y la proporcionalidad de fuerzas, tanto físicas como significantes. Su coloración adquiere connotación en cada uno de los Actos.

\section{Sonido}

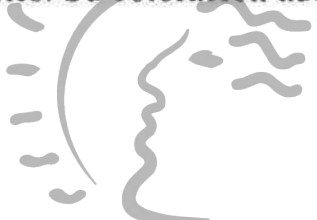

El sonido reviste gran importancia en una puesta en escena, por presencia o por ausencia. Una delasformas delsonido enZिock-Out, que hemos tratado ampliamente en otros luğar (Barrigaci1996), es) lawozs cuyos múltiples y variados matices se orientan a producir el efecto dramático de la obra y a la que César Vallejo le otorgó valor fundamental en esta pieza. El sonido puede ser negativo (en las pausas o cuando se presume uno que no es emitido o producido), y positivo (el sonido propiamente dicho). Este sonido puede ser consonante(la música), o disonante (el ruido) y supone la consideración del tiempo en que se emite o produce (Staub, 212). Trataremos el sonido disonante y su propuesta en esta obra.

Vallejo consideró el sonido que se identifica como disonante atribuyéndole cualidades del consonante, basándose en consideraciones estrictamente ideológicas. Cuando refirió sus experiencias en la Unión Soviética, narró su visita a un centro experimental, localizado en el Instituto Central del Trabajo en Moscú. Allí observó la labor de un grupo de obreros que estaban siendo entrenados en nuevas técnicas de producción en un taller en la planta baja del edificio. Fue la primera vez que relacionó el Pas d'acier de Sergei Prokofiev, «las 
sonatas de Hindemith y de Krasnancak, de Gliere», con los «sones de una extraña orquesta de batería» que era la «música del trabajo, regular, plástica, tubulada a gajos, de una cadencia elíptica y de una monotonía bárbara y grandiosa». La melodía que percibía le recordaba igualmente un «jazz-band» que culminaba apoteósicamente como "el alegretto de un oratorio hebreo de Milhaud».O en otro taller, «Un espléndido cuarteto ejecuta, vertebrado por el ritmo metálico y epiléptico de las máquinas, un trozo del tártaro Igouvnof. Aquí ya hallamos desenvolvimiento melódico. La sinfonía es ahora completa.» (1959: 42). La misma impresión tuvo cuando se enfrentó a una representación teatral en Moscú, incorporando en su percepción el sonido de las voces hablando un idioma que no conocía, lo que denominó «sinfonía de las voces, ininteligibles mezcladas a los estallidos de las máquinas» (1987: 432). Este era el «sonido del trabajo»que intentó dejar sentado en el texto de Lock-Out en la precisión de las acotaciones, desde el inicio del primer Acto, aunque fuera la primera y última referencia al sonido en él. Posteriormente solamente las voces se oirán en escena, porque los Obreros dejarán de trabajar para atender las noticias referentes al despido y cierre de lafábrica. En el segundo Acto no se hace otra acotación que lo remarque, salvo el de las voces. Una campañilla las acompaña en el Acto siguiente y füera de escena «el trotar de la caballería» $(L O, 69)$. El cuarto Acto incluye el sonido de spitazos» (72) y del pelotón de caballería que atraviesa la escena. Detonaciones de bala se escucha tras bambalinas, igual que pasos «precipitados» 0 «lentos y pesados». Los sonidos son resultado de las acciones fuera de escena. En tas de las habitaciones obreras los personajes pretenden, atentamente,resétuchaflos, porGigeros ê imperceptibles que éstos sean. El desenlace de la obra sucede entre «rumores tempestuosos entre los obreros» (88), o el sonido de las evoluciones violentas de los policía municipales. Aplausos, gritos, ovaciones y risas acompañan estas acciones, para finalmente, tal como al inicio de la obra «... se oye el sonido de las máquinas puestas a funcionar» (91).

En toda la obra el sonido está orientado a generar el clímax y la participación emotiva del espectador: ruido del pelotón de caballería, gritos y jadeo de la multitud que corre despavorida huyendo, creando lo que Vallejo señaló como «atmósfera de pánico y muerte» $(L O, 71)$. Los pitazos, ráfagas, tiros y golpes profundizan este efecto. El cabaret tiene sonidos ambientales propios del lugar, creando el clima de agitación y desenfreno. La masa obrera mantiene una voz, que emite sonidos integrados y gritos ajenos a un texto determinado.Otros sonidos son producto del desarrollo de cada una de las escenas. 
El dispositivo escénico o «decorado construido» que utiliza una puesta en escena, se constituye en las relaciones espaciales que se crean a partir del uso de instalaciones y mecanismos que se disponen en el escenario los que, en combinación con otros elementos escénicos, contribuyen a recrear el mundo de la obra teatral. El pintor alemán Oscar Schlemer, que fue Director del Departamento de Teatro y Escultura del Bauhaus desde 1920 vinculaba arquitecturaescena como un grupo interactuando orquestalmente al servicio de la creación «de un mundo imaginario y trascendental establecido sobre bases racionales» (Schlemer, 173).Y eran, precisamente, elementos de la arquitectura los que estaban siendo empleados en el teatro contemporáneo desde Jacques Copeau en 1913, con Max Littman del Teatro Nacional de Dresde en 1914, entre otros experimentos que fluctuaban entre el más estricto realismo hasta el máximo de simplificación, abstractizando los elementos compositivos, frecuentemente móviles. Contribuyó significativamente a estos experimentos el interés político de incorporar a la masa como protagonista y receptora principal de las obras,»No se trataba de ambientar, sin de a gitar» (Berthold, 252).

En Lock-Out César Vallejo propuso un entramado de corte constructivista para el primer Acto, inspirado en el teatro ruso y su efecto desacralizador. Este sistema permitía brindar nuevos espacios al movimiento del actor evitando confinarlo exclusivamentẹbl 'plaho del escenărie. Esstablecía relaciones espacio-temporales abiertas y yás flexibles concepción que correspondía ideológicamente a los planteamientos de la revolución rusa. Aparecieron andamios, escaleras, rampas, estructuras metálicas abiertas interrelacionadas entre las múltiples posibilidades que esta propuesta permite. César Vallejo propuso el uso de diferentes planos, pasarelas y varias escaleras. No especificó la distribución, tipo, altura, ni características de estos elementos. Los escalones que daban acceso a las plataformas se entendían como recursos útiles para establecer diferentes planos, que a su vez recreaban tiempos y espacios distintos.Vallejo lo utilizó en sentido psicológico, dejando a la luz el encargo de establecer los niveles espacio-temporales. Los personajes suben y bajan en función de la importancia de su parlamento en el desarrollo de la acción.

ACTO $N^{\circ}$ 1: Por las pocas referencias que da el autor deducimos que las escaleras conducen a la pasarela y a los diferentes planos en los que deben situarse los Obreros en el taller. El Vigilante y dos Obreros ocuparan sendas escaleras, lo que supone un mínimo de tres que darán acceso a plataformas donde estarán los Obreros y las máquinas que operan. Resultarán varios planos unidos por 
escaleras y rampas, a diferente altura, para crear diversos niveles de actuación. Es necesario se coloque una puerta visible a uno y otro lado del escenario para la entrada de grupos obreros que acuden a, y salen de, la concentración y para la salida de los funcionarios.

ACTO N ${ }^{\circ}$ 2: El edificio del Ministerio de Trabajo esta concebido de «muchos pisos» superpuestos $(L O, 43)$. No se determina su número ni algún elemento inusual al estructural tradicional. La oficina del Ministro ocupa el segundo nivel. Tiene puerta de entrada al fondo a la izquierda. Esta sección deberá comunicarse con la misma zona del primer nivel. Este primer nivel lo ocupan tres salas contiguas para cada uno de los grupos en conflicto y las conversaciones. Su dimensión es equivalente por recibir al mismo número de actores. Todas sobriamente decoradas. A nivel del piso del escenario, bajo las salas mencionadas, la fachada del edificio presenta un vestíbulo. El espacio en la calle deberá ser amplio para permitir el desplazamiento de los que esperan. Esta estructura múltiple superpuesta, ya considerada por Erwin Piscator (Piscator: 194 y 324) como un rémora tradicionalen 1924 , debió elegirla Vallejo por sus connotaciones ideológicas.

ACTO $N^{\circ}$ 3: Ninguna acotación especial presenta esta amplia sala para recibir a la masa obrera en el sindicato. Al extremo izquierdo refuerza la diagonal y el sentido de oposición y conflicto que marcará este Acto, una mesa y cuatro sillas sobre una plataforma de altura ligeramente superior al piso, marcando preminencia pero no imposición. En general se trata de no romper la idea de un espacio integrado, coherente y armonico.

ACTO $\mathrm{N}^{\circ}$ 4: La huelga se expone en una estructura de tres pisos superpuestos. Supone la concepción de un espacio fragmentado en el que se diseñan decorados simultáneos para escenas que se producen alternadamente y, en ocasiones brevísimas, paralelamente. La intención es presentar integralmente la huelga y los conflictos de sus protagonistas. Enfrentamos dos líneas discursivas. La general que corresponde al hecho colectivo que involucra a todos, y la particular por la que asistimos a los conflictos familiares y laborales de los Obreros contrastados con la degradación y el libertinaje de los Empresarios. En la planta baja el taller de mecánica con máquinas abandonadas. El primer nivel subdividido en tres partes. A los extremos habitaciones obreras y una calle en la central. Mobiliario mínimo. Las secciones no están relacionadas sino con la calle. La parte superior, segundo nivel, lo ocupa en toda su extensión el cabaret, con mobiliario «de lujo», con un estrado opcional para la orquesta. 
ACTO $N^{\circ}$ 5: Se inicia con la acotación «La escena anterior, plena de fulgores sangrientos» para inmediatamente agregar: «Delante de la gran puerta de la fábrica, se agrupan los obreros" (87). Como se observará, ambas plantean un problema respecto al escenario construido. Si se decide asumir «la escena anterior», es imposible que «Delante de la gran puerta de la Fábrica...» se agrupen los obreros. Implica necesariamente, una modificación para representar la "gran puerta» y ocultar el taller abandonado, por lo que no sería «la escena anterior». Nosotros optamos por la total transformación del escenario, tal como sucede con los actos precedentes. La decisión, basada en esta constante, también considera el hecho de que una gran puerta no se adapta a la estructura anterior y porque se acota «Luz roja sobre la ciudad». Esto supone que deberá destacarse este aspecto del conjunto urbano, minimizado antes por la escenografía propuesta.

El escenario construído y los elementos de mobiliario complementarios cumplirán una función integradora con el texto manteniendo el convencional realismo que propone. Las transformaciones del dispositivo escénico se realizan fuera del campo visual del público y deberáestar completamente construido cuando se levante el telón, con sus elementos de mobiliario fijos y móbiles resaltando el carácter grandilocuente de la arquitectura escénica. Las estructuras propuestas crean el clima adecuado a las acciones que en ellas se desarrollan. Tienen tanta importancia como el texto. La superposición de niveles obedece a la voluntad de Ponlarciatanto ta eseratifeacionsocial como la presión que los grupos superiores ejercen sebrelos Obreress bas ocasiones en las que están al mismo nivel la tensión entre las partes rompe en conflicto. La escenografía refleja un contraste definitorio entre ambientes serios, austeros y pobres -concordantes con la vida de los Obreros- con los formalmente fríos y elegantes del Ministerio y el frívolo, sórdido y desordenado del grupo empresarial en el cabaret.

En la división de planos que propone César Vallejo en Lock-Out encontramos forma y contenido en unidad dialéctica, coherente al proyecto ideológico propuesto. Vallejo pareció optar por darle a los planos un sentido metafórico, en afán de destacar los contenidos que el actor/personaje expone en determinados parlamentos. Algunas constantes en el empleo de los planos son:

a. Jerarquización: 1. El nivel de altura respecto al piso del escenario en que actúe el personaje dependerá del valor conceptual del discurso que emita. Las plataformas y pasarelas cumplen esta función. 
2. La estructura escénica establece el dominio de algunos planos respecto a otros, orientando la interpretación y apoyando el contenido ideológico de la obra.

b. Predominio: Se dintingue la diferenciación de planos en sentido vertical

$$
\frac{\text { DOMINACIÓN- PODER }}{\text { OPRESIÓN - SUJECIÓN }}
$$

y en sentido horizontal en las relaciones

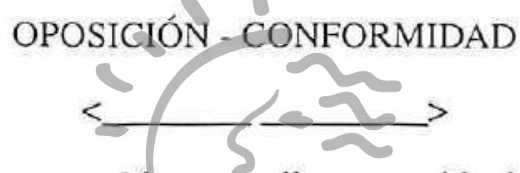

c. Equilibrio: Los planos contínuos conllevan sentido de unidad y correspondencia en el conjunto. Este equilibrio puede romperse por efecto de conflicto interno entre sus componentes, sin desvirtuar el sentido general (Acto $\mathrm{N}^{\circ} 3$ ), o quebrarse por un agente externo que produce una relación que resulta en el afianzamiento de la unldad antefior (Aetos Nos.t. y. 5 ). "Jorge Puccinelli Converso"

d. Lectura de planos verticales: La división de los pisos superpuestos de las estructuras de los Actos Nos. 2 y 4 repite el esquema de dos secciones contínuas que flanquean una tripartita. Las partes ininterrumpidas son escenario de conflicto. El nivel central tripartito representa el espacio oprimido por los otros dos.

e. Lectura de los planos horizontales: *Una acción pasiva (desplazamiento Lebranc/Delegado y los Obreros esperando en el primer nivel del Acto $\mathrm{N}^{\circ} 2$, el Vigilante y el Guardián observando motores del Acto 4; la súplica de la Obrera $\mathrm{N}^{\circ} 1$ del Acto $\mathrm{N}^{\circ} 1$, entre otros) se produciría de izquierda a derecha respecto al plano $=$ $>$

*Una acción decidida, activa, lo será en sentido contrario (El Vigilante y el Empleado avanzan a colgar el cartel. Acto $\mathrm{N}^{\circ} 1$; el chantaje Brunot/Ministro, Acto $\mathrm{N}^{\circ} 2$; la entrada de los Obreros al sindicato, Acto $\mathrm{N}^{\circ} 3$; La persecución de los Obreros, muerte de Obrera 1 y Madre 1, Acto $N^{\circ} 4$; El regreso del Delegado 
que rechaza el soborno, Acto $\mathrm{N}^{\circ} 2$; La entrada del Vigilante y el ataque del Guardián, Acto $\mathrm{N}^{\circ} 4$, por citar algunos casos. Así el plano tiene valor significativo en sí mismo $=<$ Un análisis más detallado de estos aspectos lo hemos realizado en otro trabajo (Barriga: 1995). Anotaremos sin embargo que, cada movimiento señalado en el texto y orientado por las acotaciones directas e indirectas, en ningún caso es fortuito. Cada desplazamiento tiene una carga connotativa extraordinariamente precisa a los fines que el autor perseguía.

César Vallejo seleccionó el nivel del piso del escenario como el ámbito del trabajo. El nivel medio como el del mundo de los Obreros en distintas circunstancias, y el nivel superior lo dedicó a los Industriales y al Gobierno. Entendemos en ello una clara alusión a que el trabajador se encuentra atrapado entre su centro laboral y las leyes que lo rigen en situación de desventaja y de opresión. En Lock-Out se maneja también el espacio negativo o vacío. En ocasiones el escenario queda completamente vacío o con pocos actores que permanecen mudos mientras lo atraviesan. Entre tanto-la escena se desarrolla tras bambalinas, siendo solamente-escuchada. Este marco sugiere soledad y angustia. Contrasta con las escenas de espacio positivo en las que se definen situaciones complejas. Las escenas no vistas sugieren un espacio infinitamente expandido que acentúa la percepción de abandono y extrañeza.

Considerando todos éstôsalcances êmprendemoșla dificultad de César Vallejo en conseguir se pusiera en escena su obra. Requiere la construcción de un decorado en un amplio espacio. La mayor dificultad se presenta por la magnitud de las estructuras que deberán cambiarse de un Acto a otro. Podría pensarse en un escenario móvil, pero esto modificaría la disposición ideada por el autor. La altura promedio de cinco metros para el Acto $\mathrm{N}^{\circ} 4$ y de tres metros para el Acto $\mathrm{N}^{\circ} 2$, en tanto se ajuste a los bloques compactos superpuestos, propuestos por el autor, lo requerirían tanto como el desplazamiento del alto número de actores en escena. Lock-Out es una obra espontánea de técnica teatral incipiente. Sin embargo la visión renovadora está presente en ella, aunque se dificulte la solución escénica adecuada. Esta llegará posteriormente con la mayor experiencia de su autor acerca de la índole particular del espectáculo teatral. Encontramos que en sus escritos de 1934, Notas para una estética teatral, está el resultado de sus reflexiones y muchas de las soluciones, iniciadas con la obra que hemos analizado. 


\section{BIBLIOGRAFIA CITADA}

BARRIGA TELLO, Martha

1995

Lock-Out: análisis de la puesta en escena. Tesis (Mg.). Escuela de Post-Grado. UNMSM. Facultad de Letras y Ciencias Humanas. (Inédita). Lima.

BERTHOLD, Margot

1974

Historia social del teatro. T. 2. Ediciones Guadarrama. Madrid.

BLANCHARD, Paul

1960

Historia de la dirección teatral.Compañía General Fabril Editora. Buenos Aires.

GUBERN, Roman

1971

Historia del cine. Tomo 1. Editorial Lumen. Barcelona.

HELBO, André et. al.

1978

Semiología de la representación. Editorial Gustavo Gili. Barcelena

HORMIGÓN, Juan Antomo (Reccipiladior) Converso "

1970

Investigaciones sobre el espacio escénico. Comunicación 4, (Introducción y Recopilación). Madrid.

PISCATOR, Erwin

1973 (1929) Teatro político. Instituto Cubano del Libro. La Habana.

ROMERA CASTILLO, José

1988

"Semiótica del espectáculo». En Elementos de una semiótica del texto artístico (poesía, narrativa, teatro, cine). 4a. ed. Ediciones Cátedra. Madrid.

SCHLEMMER, Oskar

1927

«La escena. Conferencia del 26.III.1927». En HORMIGÓN, op. cit., pp. 173-186. 
STAUB, August W.

1973

Creating Theatre. The art of Theatrical Directing. Harper \& Row Publishers. New York.

VALLEJO, César

1959

Rusia en 1931. Reflexiones al pie del Kremlin. Editorial Perú Nuevo. Lima.

1979

Teatro completo. Traducción y notas: Enrique Ballón Aguirre. T. 1. Pontificia Universidad Católica del Perú, Fondo Editorial. Lima.

1987

Desde Europa. Crónicas y artículos (1923-1938). Recopilación, prólogo, notas y documentación por Jorge Puccinelli. Editorial Fuente de Cultura Peruana. Lima.

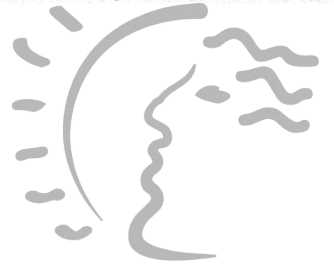

Biblioteca de Letras "Jorge Puccinelli Converso" 